\title{
Article \\ Event-Triggered Attitude-Tracking Control for a Cableless Non-Contact Close-Proximity Formation Satellite
}

\author{
Jirong Qi ${ }^{1}{ }^{\circledR}$, He Liao ${ }^{1, *}$, Yufei $\mathrm{Xu}^{2}$, Zhu Zhu ${ }^{2}$ and Chaolan You ${ }^{2}$ \\ 1 Institute of Astronautics, Nanjing University of Aeronautics and Astronautics, Nanjing 211106, China; \\ qijirong@nuaa.edu.cn \\ 2 Research Center, Shanghai Institute of Satellite Engineering, Shanghai 201109, China; \\ xyf_nuaa@126.com (Y.X.); annieapple1985@sina.com (Z.Z.); ycl_sjtu@sina.com (C.Y.) \\ * Correspondence: liaohe_crane@nuaa.edu.cn; Tel.: +86-13918211364
}

check for updates

Citation: Qi, J.; Liao, H.; Xu, Y.; Zhu, Z.; You, C. Event-Triggered Attitude-Tracking Control for a Cableless Non-Contact Close-Proximity Formation Satellite. Aerospace 2022, 9, 138. https:// doi.org/10.3390/aerospace 9030138

Academic Editor: George Z.H. Zhu

Received: 7 January 2022

Accepted: 2 March 2022

Published: 4 March 2022

Publisher's Note: MDPI stays neutral with regard to jurisdictional claims in published maps and institutional affiliations.

Copyright: (C) 2022 by the authors. Licensee MDPI, Basel, Switzerland. This article is an open access article distributed under the terms and conditions of the Creative Commons Attribution (CC BY) license (https:// creativecommons.org/licenses/by/ $4.0 /)$.

\begin{abstract}
The cablelessness of non-contact close-proximity formation satellites can fundamentally avoid the influence of non-contact interface coupling effects and can further enhance the attitude pointing accuracy and stability of the payload module (PM). However, it also brings the problem of limited on-board resources and system latency. In this paper, an event-triggered attitude tracking controller of the support module (SM) that avoids the Zeno phenomenon was proposed. The update time of the control signal was determined by the event-triggering mechanism based on intermediate variables, thus, reducing the communication burden and actuator asynchrony between the two modules. The feasibility and effectiveness of the proposed approach was demonstrated by numerical simulations.
\end{abstract}

Keywords: non-contact close-proximity formation satellite; attitude tracking controller; eventtriggering mechanism

\section{Introduction}

The non-contact close-proximity formation satellite, consisting of a PM and an SM separated by the non-contact Lorentz actuator (NCLA), has significant application potential and can provide a satellite platform with ultra-high attitude pointing accuracy and stability for space gravitational wave detection [1,2], next-generation space telescopes [3,4], and other space exploration missions [5,6].

Due to the remarkable attitude control performance, non-contact satellites have become an attractive research direction. Lockheed Martin built a single rotation degree-offreedom and two translation degree-of-freedom system based on planar air-bearing to verify the concept of a non-contact satellite platform [7], but it was not sufficient to verify the control problem under multi-dynamic coupling. In recent years, linear feedback proportion differentiation (LFPD) control [8], twistor-based synchronous control [9], and active disturbance rejection control (ADRC) [10] based on Newton Euler modeling approaches have been used to solve the multi-body dynamics coupling control problem. Meanwhile, advanced control methods such as optimal control, fuzzy control and deep reinforcement learning have been successfully applied in various complex nonlinear control systems, which can provide effective solutions for spacecraft control [11-13].

However, previous research has equipped cables between the two modules. The coupling effect of the non-contact interface created by the translational and torsional stiffness of the cable affects the attitude control performance of the PM [14-17], which contradicts the original purpose of the non-contact design. In addition, the analysis of the cable effects is included in the on-orbit validation of the non-contact platform by Lockheed Martin [18]. Furthermore, the development of wireless communication and wireless energy transmission technologies can provide the technical support for cable-free non-contact close-proximity formation satellites [19-21]. Moreover, the widespread application of 
plug-and-play accessories and modularity have become trends of future spacecrafts [22,23]. Under this condition, although cablelessness can avoid non-contact interface coupling effects, it also brings problems such as limited on-board resources, communication time delay, and actuator asynchrony [24]. Therefore, the research of control methods for noncontact close-proximity formation satellites under cableless condition is an urgent problem to be solved.

On the other hand, from the perspective of on-orbit applications, the non-contact closeproximity formation satellites requires an initial release from the contact configuration after orbiting. Due to the small air-clearance constraint of the NCLA, this process needs to achieve a rapid tracking control of the SM so that the NCLA can quickly enter the linear range. Considering the in-flight fluttering of the solar panel and the control lumping of the actuator installed in the SM, as well as the complex space environment, it is necessary to monitor the relative attitude and position information of the two modules and to update the control signals at a high frequency during the release process, although it will waste some on-board resources. When the release process is completed, the SM will perform "less demanding" close formation tracking control. At this time, the entire satellite state tends to be stabilized; if it is possible to reduce the update frequency of the SM control signal, the delay problems caused by the software and hardware can be further reduced and the SM tracking control can be accomplished more effectively.

Meanwhile, the control methods involved in the existing research are all periodic sampling control methods. In this control strategy, the control signals are updated periodically whether it is necessary or not, which is a waste of communication resources. Considering the various constraints that exist under cableless conditions, control strategies with frequent communication are difficult to achieve in practical engineering. Event-triggered control provides a solution to the control problem in the presence of resource constraint [25-28]. In event-triggered control, the update moment of the control signal is determined by the triggering mechanism, which can effectively reduce the communication frequency.

Motivated by the above-mentioned research, in this paper, we proposed an eventtriggered attitude tracking control for a cableless non-contact close-proximity formation satellite and avoid the Zeno phenomenon. First, compared with existing non-contact satellite research, the cable-free design can fundamentally avoid the coupling effect of a non-contact interface due to translational and torsional stiffness. Secondly, the eventtriggered tracking control significantly reduces the update frequency of the control signal and alleviates the communication burden between the two modules, so that the SM can effectively achieve the tracking control with the smallest communication bandwidth occupation. Simultaneously, the NCLA is always maintained in the linear range during the whole control process, which provides a guarantee for the high-precision attitude control performance of the PM.

The rest of this paper is organized as follows. The problem statement of this paper is given in Section 2. The design of the controller is introduced in Section 3. In Section 4, the numerical simulation is performed to demonstrate the feasibility and effectiveness of the proposed approach. Finally, the main conclusions are given in Section 5.

\section{Problem Statement}

\subsection{Hierarchical Architecture}

In contrast to conventional fixed-linked satellites and the Stewart platform [29], cableless non-contact close-proximity formation satellites consist of the PM and the SM separated by the NCLA, as shown in Figure 1. The coil part of the NCLA, a star sensitive position receiver and an ultra-quiet payload were installed in the PM; the magnet part of the NCLA, the control moment gyro, the solar panel, and other components were installed in the SM. Moreover, both modules were equipped with a communication device for data transmission. Special attention was paid to the fact that there were no cables between the two modules, avoiding the non-contact interface coupling effects on the attitude control performance of the PM. In addition, the NCLA adopted in this architecture was a linear 
actuator with direct current drive, which had a higher control accuracy than the control moment gyro (CMG) [30,31].

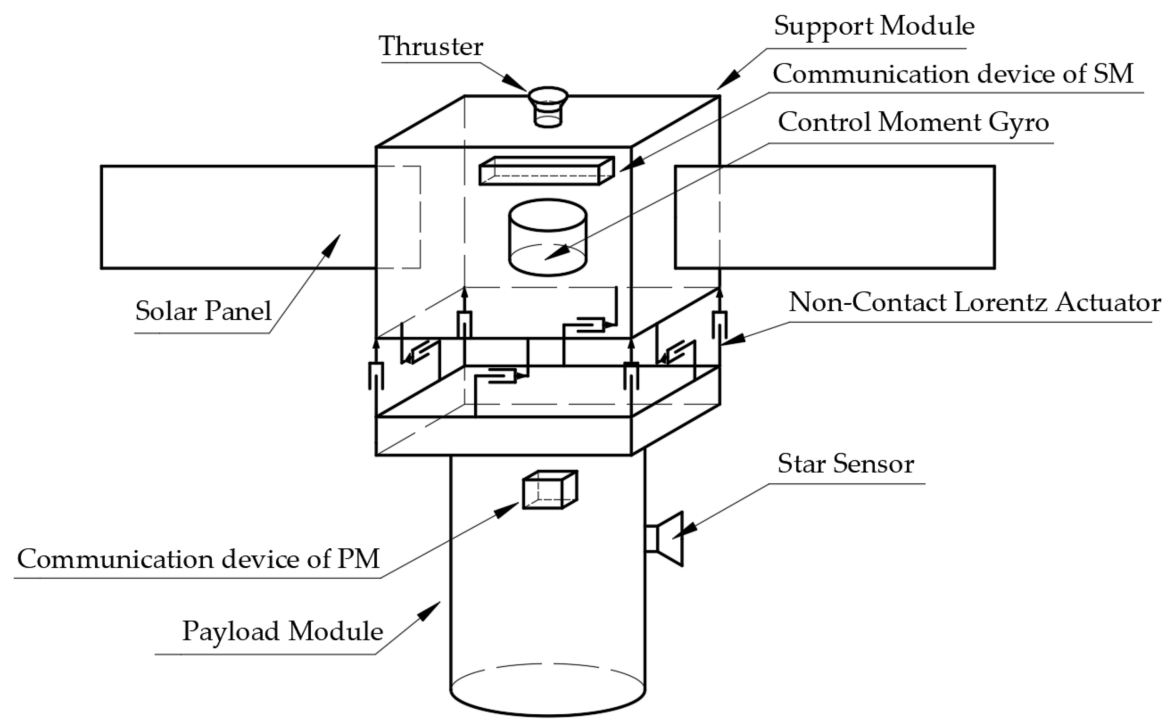

Figure 1. The architecture design of the cableless non-contact close-proximity formation satellite.

\subsection{Dynamics Modeling}

In order to discuss the motion of the cableless non-contact close-proximity formation satellite, the J2000.0 equatorial frame Oixiyizi was defined as the inertial coordinate system. The tracking coordinate system of the stability control was a Cartesian right-handed frame fixed to the local orbital frame of the PM Ooxoyozo, in which the origin was fixed at the center mass of the PM. The body frame of the PM Opxpypzp and the body frame of the SM Osxsyszs were defined as the Cartesian right-handed frames fixed to the mass distribution and geometry, respectively. The overall definition of the coordinate system of the cableless non-contact close-proximity formation satellite is shown in Figure 2.

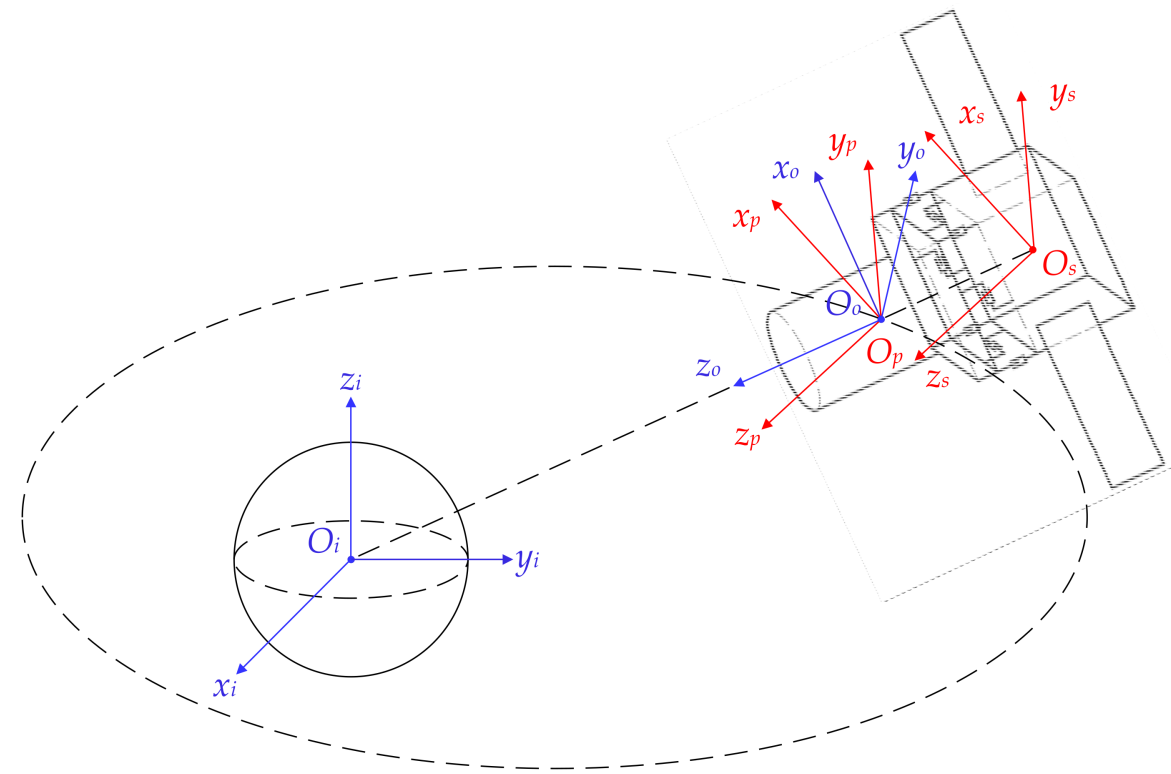

Figure 2. Coordinate definition of the cableless non-contact close-proximity formation satellite. 
According to the architecture shown in Figures 1 and 2, the dynamics are given in terms of a quaternion as follows, based on our previous research [10,32]:

$$
\begin{aligned}
& \dot{\mathrm{q}}_{\mathrm{po}, \mathrm{pl}}=-\frac{1}{2} \mathbf{q}_{\mathrm{po}, \mathrm{p}}^{\mathrm{T}} \boldsymbol{\omega}_{\mathrm{po}, \mathrm{p}} \\
& \dot{\mathbf{q}}_{\mathrm{po}, \mathrm{p}}=\frac{1}{2}\left(\mathbf{q}_{\mathrm{po}, \mathrm{p}}^{\times} \boldsymbol{\omega}_{\mathrm{po,p}}+\mathbf{q}_{\mathrm{po}, \mathrm{p}} \mathbf{I}_{3 \times 3} \boldsymbol{\omega}_{\mathrm{po}, \mathrm{p}}\right) \\
& \dot{\omega}_{\mathrm{p}, \mathrm{p}}=\mathrm{J}_{\mathrm{p}}^{-1}\left(\tau_{\mathrm{p}}+\tau_{\mathrm{dp}}+\Delta \tau-\omega_{\mathrm{pi}, \mathrm{p}}^{\times} \mathrm{J}_{\mathrm{p}} \omega_{\mathrm{pi}, \mathrm{p}}\right)+\omega_{\mathrm{po}, \mathrm{p}}^{\times} \mathrm{C}_{\mathrm{po}} \omega_{\mathrm{oi}, \mathrm{o}}-\mathrm{C}_{\mathrm{po}} \dot{\omega}_{\mathrm{oi}, \mathrm{o}} \\
& \dot{\mathrm{q}}_{\mathrm{sp}, \mathrm{s} 1}=-\frac{1}{2} \mathbf{q}_{\mathrm{sp}, \mathrm{s}}^{\mathrm{T}} \boldsymbol{\omega}_{\mathrm{sp}, \mathrm{s}} \\
& \dot{\mathbf{q}}_{\mathrm{sp}, \mathrm{s}}=\frac{1}{2}\left(\mathbf{q}_{\mathrm{sp}, \mathrm{s}}^{\times} \boldsymbol{\omega}_{\mathrm{sp}, \mathrm{s}}+\mathbf{q}_{\mathrm{sp}, \mathrm{s}} \mathrm{i}_{3 \times 3} \boldsymbol{\omega}_{\mathrm{sp}, \mathrm{s}}\right) \\
& \dot{\omega}_{\mathrm{sp}, \mathrm{s}}=\mathbf{J}_{\mathrm{s}}^{-1}\left[\tau_{\mathrm{s}}+\tau_{\mathrm{ds}}-\mathrm{C}_{\mathrm{sp}}\left(\tau_{\mathrm{p}}+\Delta \tau\right)-\Delta_{\mathrm{a} 1} \ddot{\eta}_{\mathrm{a} 1}-\Delta_{\mathrm{a} 2} \ddot{\eta}_{\mathrm{a} 2}\right. \\
& \left.-\omega_{\mathrm{si}, \mathrm{s}}^{\times}\left(J_{\mathrm{s}} \omega_{\mathrm{si}, \mathrm{s}}+\mathbf{h}_{c}\right)\right]+\omega_{\mathrm{sp}, \mathrm{s}}^{\times} \mathrm{C}_{\mathrm{sp}} \omega_{\mathrm{pi}, \mathrm{p}}-\mathrm{C}_{\mathrm{sp}} \dot{\omega}_{\mathrm{pi}, \mathrm{p},}
\end{aligned}
$$

where $\mathrm{q}_{\mathrm{sp}, \mathrm{s} 1} \in \mathbb{R}^{1 \times 1}$ and $\mathbf{q}_{\mathrm{sp}, \mathrm{s}} \in \mathbb{R}^{3 \times 1}$ denote the scalar part and vector part of the quaternion of the SM, respectively; $\mathbf{q}_{\mathrm{po}, \mathrm{p} 1} \in \mathbb{R}^{1 \times 1}$ and $\mathbf{q}_{\mathrm{po}, \mathrm{p}} \in \mathbb{R}^{3 \times 1}$ denote the scalar part and vector part of the quaternion of the PM, respectively; $\omega_{\mathrm{sp}, \mathrm{s}} \in \mathbb{R}^{3 \times 1}$ denotes the angular velocity of the SM frame relative to the PM frame; $\omega_{\text {si,s }} \in \mathbb{R}^{3 \times 1}$ denotes the angular velocity of the SM frame relative to the inertial frame; $\boldsymbol{\omega}_{\mathrm{po}, \mathrm{p}} \in \mathbb{R}^{3 \times 1}$ denotes the angular velocity of the PM frame relative to the orbital frame; $\omega_{\text {pi,p }} \in \mathbb{R}^{3 \times 1}$ denotes the angular velocity of the PM frame relative to the inertial frame; $\omega_{\mathrm{oi}, \mathrm{o}} \in \mathbb{R}^{3 \times 1}$ denotes the angular velocity of the orbital frame relative to the inertial frame; $\mathbf{J}_{\mathrm{s}}$ and $\mathbf{J}_{\mathrm{p}} \in \mathbb{R}^{3 \times 3}$ denote the inertia matrix of the SM and PM, respectively; $\mathbf{h}_{c} \in \mathbb{R}^{3 \times 1}$ denotes the angular momentum of the CMG installed in the SM; $\tau_{\mathrm{s}}$ and $\tau_{\mathrm{p}} \in \mathbb{R}^{3 \times 1}$ denote the control torque of the SM and PM, respectively; $\Delta \tau \in \mathbb{R}^{3 \times 1}$ denotes the inner disturbance torque generated by the NCLA; $\tau_{\mathrm{ds}}$ and $\tau_{\mathrm{dp}} \in \mathbb{R}^{3 \times 1}$ denotes the external disturbance torque of the SM and PM, respectively; $\mathbf{C}_{\mathrm{sp}}$ and $\mathbf{C}_{\text {po }} \in \mathbb{R}^{3 \times 3}$ denotes the transformation matrix, which can be expressed as:

$$
\begin{aligned}
& \mathbf{C}_{\mathrm{sp}}=\left(\mathrm{q}_{\mathrm{sp}, \mathrm{s} 1}^{2}-\mathbf{q}_{\mathrm{sp}, \mathrm{s}}^{\mathrm{T}} \mathbf{q}_{\mathrm{sp}, \mathrm{s}}\right) \mathbf{I}_{3 \times 3}+2 \mathbf{q}_{\mathrm{sp}, \mathrm{s}} \mathbf{q}_{\mathrm{sp}, \mathrm{s}}^{\mathrm{T}}-2 \mathrm{q}_{\mathrm{sp}, \mathrm{s} 1} \mathbf{q}_{\mathrm{sp}, \mathrm{s}}^{\times} \\
& \mathrm{C}_{\mathrm{po}}=\left(\mathrm{q}_{\mathrm{po}, \mathrm{pl}}^{2}-\mathbf{q}_{\mathrm{po}, \mathrm{p}}^{\mathrm{T}} \mathbf{q}_{\mathrm{po}, \mathrm{p}}\right) \mathbf{I}_{3 \times 3}+2 \mathbf{q}_{\mathrm{po}, \mathrm{p}} \mathbf{q}_{\mathrm{po}, \mathrm{p}}^{\mathrm{T}}-2 \mathrm{q}_{\mathrm{po}, \mathrm{p}} \mathbf{q}_{\mathrm{po}, \mathrm{p}}^{\mathrm{T}} .
\end{aligned}
$$

The notation $\alpha^{\times}$for a vector $\alpha=\left[\alpha_{1}, \alpha_{2}, \alpha_{3}\right]^{\mathrm{T}}$ denotes a cross-product of a skewsymmetric expressed as:

$$
\boldsymbol{\alpha}^{\times}=\left[\begin{array}{ccc}
0 & -\alpha_{3} & \alpha_{2} \\
\alpha_{3} & 0 & -\alpha_{1} \\
-\alpha_{2} & \alpha_{1} & 0
\end{array}\right] .
$$

In addition, $\Delta_{\text {ai }}$ and $\eta_{\text {ai }}(i=1,2)$ denote the coupling matrix and the modality of the solar panel, which are, respectively, expressed as:

$$
\left\{\begin{array}{l}
\ddot{\eta}_{\mathrm{a} 1}+2 \zeta_{\mathrm{a}} \Lambda_{\mathrm{a}} \dot{\eta}_{\mathrm{a} 1}+\Lambda_{\mathrm{a}}^{2} \eta_{\mathrm{a} 1}+\Delta_{\mathrm{a} 1}^{\mathrm{T}} \dot{\boldsymbol{\omega}}_{\mathrm{si}, \mathrm{s}}=0 \\
\ddot{\eta}_{\mathrm{a} 2}+2 \zeta_{\mathrm{a}} \Lambda_{\mathrm{a}} \dot{\eta}_{\mathrm{a} 2}+\Lambda_{\mathrm{a}}^{2} \eta_{\mathrm{a} 2}+\Delta_{\mathrm{a} 2}^{\mathrm{T}} \dot{\boldsymbol{\omega}}_{\mathrm{si}, \mathrm{s}}=0,
\end{array}\right.
$$

where $\zeta_{\mathrm{a}}$ denotes the damping coefficient matrix and $\boldsymbol{\Lambda}_{\mathrm{a}}$ dentoes the modal frequency diagonal matrix.

\subsection{Control Strategy Analysis}

According to the dynamics shown in Equations (1)-(6), the PM can be considered as a rigid body. In this non-contact architecture, unprecedented attitude control accuracy and stability can be achieved using ADRC or LFPD control; its feasibility has been demonstrated in our previous research [10,32]. From the perspective of engineering application, we design 
actived attitude control law for the PM based on the conventional time-triggered LFPD control as follows:

$$
\begin{aligned}
& \tau_{\mathrm{p}}=-\mathbf{K}_{\mathrm{pp}} \mathbf{q}_{\mathrm{po}, \mathrm{p}}-\mathbf{K}_{\mathrm{dp}} \boldsymbol{\omega}_{\mathrm{po}, \mathrm{p}}+\Delta_{\mathrm{p}} \\
& \Delta_{\mathrm{p}}=-\boldsymbol{\tau}_{\mathrm{dp}}+\Delta \tau+\omega_{\mathrm{pi}, \mathrm{p}}^{\times} \mathbf{J}_{\mathrm{p}} \boldsymbol{\omega}_{\mathrm{pi}, \mathrm{p}}-\mathbf{J}_{\mathrm{p}}\left(\boldsymbol{\omega}_{\mathrm{po}, \mathrm{p}}^{\times} \mathrm{C}_{\mathrm{po}} \boldsymbol{\omega}_{\mathrm{oi}, \mathrm{o}}\right)+\mathrm{J}_{\mathrm{p}} \mathrm{C}_{\mathrm{po}} \dot{\omega}_{\mathrm{oi}, \mathrm{o}}
\end{aligned}
$$

where $K_{i}=\operatorname{diag}\left(K_{i x}, K_{i y}, K_{i z}\right) \in \mathbb{R}^{3 \times 3}, \mathrm{i} \in\{p p, d p\}$ denotes the positive definite matrix, and $\Delta_{\mathrm{p}}$ denotes a linear feedback term.

In previous research on non-contact close-proximity formation satellites, the two modules have been equipped with cables. The non-contact interface coupling effect due to the translational and torsional stiffness of the cable would influence the attitude control performance of the PM. In this paper, cables are not considered; data and energy are transmitted between the two modules via wireless devices. However, this also brings the problem of constrained on-board resources and system latency. Under these conditions, the period sampling controller used in previous studies could fail, causing the NCLA to enter the nonlinear range. In extreme cases, the two modules may collide. To avoid this situation, the SM needs to achieve attitude tracking control with a reduced number of communications to avoid collision between the two modules. Therefore, in this paper, the SM controller design will be based on event-triggered theory, so that the SM can complete attitude tracking control while meeting the above requirements. At the same time, the relative attitude angles of the two modules should be maintained in the linear range of the NCLA, which guarantees excellent attitude control performance of the PM.

The closed-loop control system is shown in Figure 3. The whole system consists of active control of the PM and cooperative control of the SM. A high-precision star sensor can be used to determine the attitude of the PM. Due to the rigid body characteristics of the PM, it can accomplish ultra-high precision active attitude control through the NCLA. The noncontact sensors can be used to solve the relative attitude of the two modules and transmitted wirelessly to the SM; then, the ETC based tracking controller, mainly including triggering mechanism, LFPD and zero-order holder $(\mathrm{ZOH})$, make event-triggered determination based on the state error and send the control signal to the actuators to complete the tracking control.

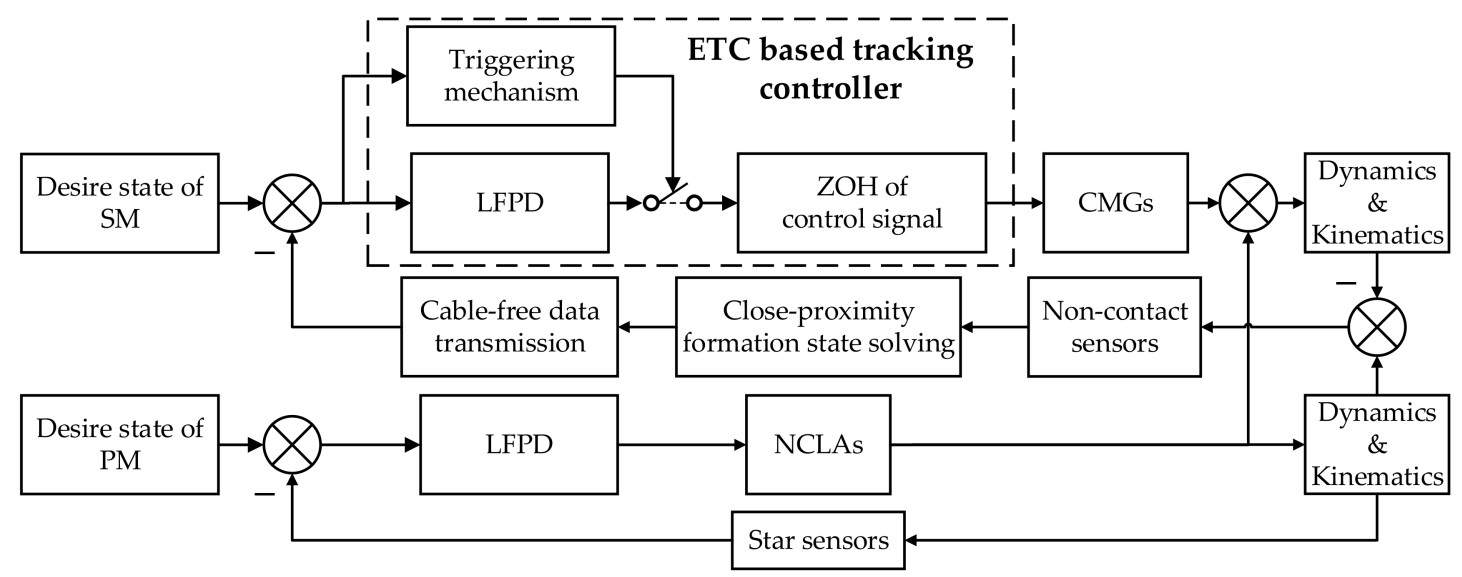

Figure 3. PM closed-loop control system.

The control objective can be described as follows: considering the tracking dynamics described by Equations (3) and (4), design control scheme $\tau_{\mathrm{s}}$ that the SM can track PM with an acceptable accuracy and the closed-loop system should be globally asymptotically stable, and $\lim _{\mathrm{T} \rightarrow \infty}\left[\mathrm{q}_{\mathrm{sp}, \mathrm{s} 1}, \mathrm{q}_{\mathrm{sp}, \mathrm{s}}\right]=[1,0,0,0]^{\mathrm{T}}, \lim _{\mathrm{T} \rightarrow \infty} \boldsymbol{\omega}_{\mathrm{sp}, \mathrm{s}}=0$.

Meanwhile, to demonstrate the stability of the closed-loop system, the following assumption is introduced. 
Assumption 1. Combining the actual tracking control of the SM and the in-flight environment, the disturbance is bounded and differentiable, which indicates the equation $\left\|\boldsymbol{\tau}_{\mathrm{ds}}\right\| \leq \mathrm{d}_{1},\left\|\boldsymbol{\tau}_{\mathrm{dp}}\right\| \leq \mathrm{D}_{2}$ and $\|\Delta \tau\| \leq \mathrm{D}_{3}$ holds, where $\|\cdot\|$ denotes the Euclidean norm of a vector.

\section{ETC Based Tracking Controller}

\subsection{Controller Design}

For the event-triggered control, the control signal $\tau_{\mathrm{s}}$ will be updated at $t_{\mathrm{k}}, \mathrm{k} \in \mathrm{Z}^{+}$ when the triggering mechanism is satisfied. The control signal will be maintained at a constant value by a zero-order $(\mathrm{ZOH})$ when $t \in\left[\mathrm{t}_{\mathrm{k}}, \mathrm{t}_{\mathrm{k}+1}\right)$, which can be expressed as:

$$
\tau_{\mathrm{s}}(\mathrm{t})=\tau_{\mathrm{cons}}\left(\mathrm{t}_{\mathrm{k}}\right),
$$

where $\tau_{\text {cons }}$ denotes the designed control law.

To facilitate the design of the triggering mechanism, defining state variables as follows:

$$
\begin{gathered}
\Delta \tau_{\mathrm{s}}=\boldsymbol{\tau}_{\mathrm{s}}(\mathrm{t})-\boldsymbol{\tau}_{\mathrm{cons}}(\mathrm{t}) \\
\mathbf{X}=\boldsymbol{\omega}_{\mathrm{sp}, \mathrm{s}}+\delta \mathbf{q}_{\mathrm{sp}, \mathrm{s}}
\end{gathered}
$$

Thus, the triggering instants can be determined by the following condition:

$$
\mathrm{t}_{\mathrm{k}+1}=\inf \left\{\mathrm{t}>\mathrm{t}_{\mathrm{k}} \mid\left\|\Delta \boldsymbol{\tau}_{\mathrm{s}}\right\| \geq \varepsilon\|X\|\right\}
$$

where $\delta, \varepsilon$ denote positive numbers.

Moreover, we designed the control law for the attitude tracking control of the SM as follows:

$$
\boldsymbol{\tau}_{\mathrm{cons}}(\mathrm{t})=-\mathbf{K}_{\mathrm{ps}} \mathbf{q}_{\mathrm{sp}, \mathrm{s}}-\mathbf{K}_{\mathrm{ds}} \boldsymbol{\omega}_{\mathrm{sp}, \mathrm{s}}+\Delta_{\mathrm{s}},
$$

where $\mathbf{K}_{\mathrm{i}}=\operatorname{diag}\left(\mathrm{K}_{\mathrm{ix}}, \mathrm{K}_{\mathrm{iy}}, \mathrm{K}_{\mathrm{iz}}\right) \in \mathbb{R}^{3 \times 3}, \mathrm{i} \in\{\mathrm{ps}, \mathrm{ds}\}$ denotes the positive definite matrix, and $\Delta_{\mathrm{s}}$ denotes a linear feedback term, which is given by:

$$
\begin{aligned}
\Delta_{\mathrm{s}}= & -\boldsymbol{\tau}_{\mathrm{d}}+\mathrm{C}_{\mathrm{sp}}\left(\boldsymbol{\tau}_{\mathrm{p}}+\Delta \boldsymbol{\tau}\right)+\boldsymbol{\Delta}_{\mathrm{a} 1} \ddot{\eta}_{\mathrm{a} 1}+\boldsymbol{\Delta}_{\mathrm{a} 2} \ddot{\eta}_{\mathrm{a} 2} \\
& +\boldsymbol{\omega}_{\mathrm{si}, \mathrm{s}}^{\times}\left(\mathbf{J}_{\mathrm{s}} \boldsymbol{\omega}_{\mathrm{si}, \mathrm{s}}+\mathbf{h}_{\mathrm{c}}\right)-\mathrm{J}_{\mathrm{s}}\left(\boldsymbol{\omega}_{\mathrm{sp}, \mathrm{s}}^{\times} \mathrm{C}_{\mathrm{sp}} \boldsymbol{\omega}_{\mathrm{pi}, \mathrm{p}}\right)+\mathrm{J}_{\mathrm{s}}\left(\mathbf{C}_{\mathrm{sp}} \dot{\boldsymbol{\omega}}_{\mathrm{pi}, \mathrm{p}}\right)
\end{aligned}
$$

Remark 1. We considered the SM attitude tracking control problem after the initial release, when the state of the non-contact close-proximity formation satellite tended to be stabilized. Therefore, the LFPD, which is widely used in engineering, was adopted as the tracking controller.

\subsection{Feasibility Analysis}

In this section, we analyze the feasibility of the event-triggering mechanism and the controller designed in Section 3.1, mainly including the stability analysis of the closed-loop system and the avoidance of the Zeno phenomenon.

Theorem 1. The tracking controller of the SM given by Equation (12) and the active attitude controller of the PM given by Equation (7) under the Assumption 1 was globally asymptotically stable.

Theorem 2. For the attitude triggering mechanism given by Equation (11), there always existed a positive lower boundary for any two neighboring triggering instants under the Assumption 1 , which guaranteed Zeno-free. That for $\forall \mathrm{k}$, the equation $\mathrm{t}_{\mathrm{k}+1}-\mathrm{t}_{\mathrm{k}} \geq \mathrm{t}^{*}$ holds, where $\mathrm{t}^{*}$ is $a$ positive constant.

Proof of Theorem 1. Define auxiliary variable $\mathbf{Q}_{\mathrm{s}}=\left[1-\mathrm{q}_{\mathrm{sp}, \mathrm{s} 1}, \mathbf{q}_{\mathrm{sp}, \mathrm{s}}^{\mathrm{t}}\right]^{\mathrm{t}}$, define the Lyapunov function as follows:

$$
\mathrm{V}=\frac{1}{2} \boldsymbol{\omega}_{\mathrm{sp}, \mathrm{s}}^{T} \mathbf{J}_{\mathrm{s}} \boldsymbol{\omega}_{\mathrm{sp}, \mathrm{s}}+\frac{1}{2} \mathrm{~K}_{\mathrm{p}} \mathbf{Q}_{\mathrm{s}}^{\mathrm{T}} \mathbf{Q}_{\mathrm{s}} .
$$


Thus, the first derivative of Equation (14) can be obtained as:

$$
\begin{aligned}
\dot{\mathrm{V}}= & \boldsymbol{\omega}_{\mathrm{sp}, \mathrm{s}}^{\mathrm{T}} \mathbf{J}_{\mathrm{s}} \dot{\boldsymbol{\omega}}_{\mathrm{sp}, \mathrm{s}}+\mathbf{K}_{\mathrm{p}} \mathbf{Q}_{\mathrm{s}}^{\mathrm{T}} \dot{\mathbf{Q}}_{\mathrm{s}} \\
= & \boldsymbol{\omega}_{\mathrm{sp}, \mathrm{s}}^{\mathrm{T}}\left[\boldsymbol{\tau}_{\mathrm{s}}+\boldsymbol{\tau}_{\mathrm{d}}-\mathbf{C}_{\mathrm{ps}}\left(\boldsymbol{\tau}_{\mathrm{p}}+\Delta \boldsymbol{\tau}\right)-\boldsymbol{\Delta}_{\mathrm{a} 1} \ddot{\eta}_{\mathrm{a} 1}-\boldsymbol{\Delta}_{\mathrm{a} 2} \ddot{\eta}_{\mathrm{a} 2}\right. \\
& \left.-\boldsymbol{\omega}_{\mathrm{si}, \mathrm{s}}^{\times}\left(\mathbf{J}_{\mathrm{s}} \boldsymbol{\omega}_{\mathrm{si}, \mathrm{s}}+\mathbf{h}_{\mathrm{c}}\right)+\mathbf{J}_{\mathrm{s}}\left(\boldsymbol{\omega}_{\mathrm{sp}, \mathrm{s}}^{\times} \mathbf{C}_{\mathrm{ps}} \boldsymbol{\omega}_{\mathrm{pi}, \mathrm{p}}\right)-\mathbf{J}_{\mathrm{s}}\left(\mathbf{C}_{\mathrm{ps}} \mathbf{J}_{\mathrm{p}}^{-1} \dot{\boldsymbol{\omega}}_{\mathrm{pi}, \mathrm{p}}\right)\right] \\
& +\mathbf{K}_{\mathrm{p}}\left[1-\mathrm{q}_{\mathrm{sp}, \mathrm{s} 1}, \mathbf{q}_{\mathrm{sp}, \mathrm{s}}^{\mathrm{T}}\right]\left[\frac{1}{2} \mathbf{q}_{\mathrm{sp}, \mathrm{s}}^{\mathrm{T}} \boldsymbol{\omega}_{\mathrm{sp}, \mathrm{s}}\left(\frac{1}{2} \mathbf{q}_{\mathrm{sp}, \mathrm{s}}^{\times} \boldsymbol{\omega}_{\mathrm{sp}, \mathrm{s}}+\frac{1}{2} \mathrm{q}_{\mathrm{sp}, \mathrm{s} 1} \mathbf{I}_{3 \times 3} \boldsymbol{\omega}_{\mathrm{sp}, \mathrm{s}}\right)^{\mathrm{T}}\right] \\
= & \boldsymbol{\omega}_{\mathrm{sp}, \mathrm{T}}^{\mathrm{T}}\left[\boldsymbol{\tau}_{\mathrm{s}}+\boldsymbol{\tau}_{\mathrm{d}}-\mathbf{C}_{\mathrm{ps}}\left(\boldsymbol{\tau}_{\mathrm{p}}+\Delta \boldsymbol{\tau}\right)-\boldsymbol{\Delta}_{\mathrm{a} 1} \ddot{\eta}_{\mathrm{a} 1}-\boldsymbol{\Delta}_{\mathrm{a} 2} \ddot{\eta}_{\mathrm{a} 2}\right. \\
& \left.-\boldsymbol{\omega}_{\mathrm{si}, \mathrm{s}}^{\times}\left(\mathbf{J}_{\mathrm{s}} \boldsymbol{\omega}_{\mathrm{si}, \mathrm{s}}+\mathbf{h}_{\mathrm{c}}\right)+\mathbf{J}_{\mathrm{s}}\left(\boldsymbol{\omega}_{\mathrm{sp}, \mathrm{s}}^{\times} \mathbf{C}_{\mathrm{ps}} \boldsymbol{\omega}_{\mathrm{pi}, \mathrm{p}}\right)-\mathbf{J}_{\mathrm{s}}\left(\mathbf{C}_{\mathrm{ps}} \mathbf{J}_{\mathrm{p}}^{-1} \dot{\boldsymbol{\omega}}_{\mathrm{pi}, \mathrm{p}}\right)\right] \\
& +\mathbf{K}_{\mathrm{p}} \mathbf{q}_{\mathrm{sp}, \mathrm{s}}^{\mathrm{T}} \boldsymbol{\omega}_{\mathrm{sp}, \mathrm{s}} .
\end{aligned}
$$

Substituting Equation (12) into Equation (15), we can obtain:

$$
\begin{aligned}
\dot{\mathrm{V}} & =\boldsymbol{\omega}_{\mathrm{sp}, \mathrm{s}}^{\mathrm{T}}\left[-\mathbf{K}_{\mathrm{p}} \mathbf{q}_{\mathrm{sp}, \mathrm{s}}-\mathrm{K}_{\mathrm{d}} \boldsymbol{\omega}_{\mathrm{sp}, \mathrm{s}}\right]+\mathbf{K}_{\mathrm{p}} \mathbf{q}_{\mathrm{sp}, \mathrm{s}}^{\mathrm{t}} \boldsymbol{\omega}_{\mathrm{sp}, \mathrm{s}} \\
& =\boldsymbol{\omega}_{\mathrm{sp}, \mathrm{s}}^{\mathrm{T}}\left[-\mathbf{K}_{\mathrm{p}} \mathbf{q}_{\mathrm{sp}, \mathrm{s}}-\mathbf{K}_{\mathrm{d}} \boldsymbol{\omega}_{\mathrm{sp}, \mathrm{s}}+\mathbf{K}_{\mathrm{p}} \mathbf{q}_{\mathrm{sp}, \mathrm{s}}\right] \\
& =-\mathbf{K}_{\mathrm{d}} \boldsymbol{\omega}_{\mathrm{sp}, \mathrm{s}}^{\mathrm{T}} \boldsymbol{\omega}_{\mathrm{sp}, \mathrm{s}} \\
& \leq 0 .
\end{aligned}
$$

According to Lassale's invariant set principle, when $t \rightarrow \infty$, the following relation can be guaranteed: $\boldsymbol{\omega}_{\mathrm{sp}, \mathrm{s}} \rightarrow 0, \mathrm{q}_{\mathrm{sp}, \mathrm{s}} \rightarrow 0,1-\mathrm{q}_{\mathrm{sp}, \mathrm{s} 1} \rightarrow 0, \mathrm{q}_{\mathrm{sp}, \mathrm{s} 1} \rightarrow 1$. Therefore, it can be concluded that the attitude tracking control of the SM was globally asymptotically stable.

The stability analysis for the controller given by Equation (7) is the same as above.

Proof of Theorem 2. Through the triggering mechanism designed in Section 3.1, it was straightforward to determine that the control signal error $\Delta \boldsymbol{\tau}_{\mathrm{s}}$ was reset to zero at each triggering instant $t=t_{k}$. Meanwhile, we know that $\dot{\tau}_{s}(t)=0$ always holds for a certain triggering time interval $t \in\left[t_{k}, t_{k+1}\right)$. Thus, the time derivative of $\left\|\Delta \tau_{s}\right\|$ can be expressed as:

$$
\frac{\mathrm{d}}{\mathrm{dt}}\left\|\Delta \tau_{\mathrm{s}}\right\|=\frac{\mathrm{d}}{\mathrm{dt}} \sqrt{\Delta \boldsymbol{\tau}_{\mathrm{s}}^{\mathrm{t}} \Delta \boldsymbol{\tau}_{\mathrm{s}}}=\frac{\Delta \boldsymbol{\tau}_{\mathrm{s}}^{\mathrm{T}}}{\left\|\Delta \tau_{\mathrm{s}}\right\|} \Delta \dot{\tau}_{\mathrm{s}} \leq\left\|\Delta \dot{\tau}_{\mathrm{s}}\right\|=\left\|\dot{\tau}_{\mathrm{s}}(\mathrm{t})-\dot{\tau}_{\text {cons }}(\mathrm{t})\right\|=\left\|\dot{\tau}_{\text {cons }}(\mathrm{t})\right\|
$$

According to Assumption 1 and Equation (12), $\boldsymbol{\tau}_{\text {cons }}(t)$ is bound and differentiable. Therefore, we can assume that there exists a positive constant $\gamma$ satisfies $\left\|\boldsymbol{\tau}_{\text {cons }}(t)\right\| \leq \gamma$, integrate both sides of Equation (17), we can obtain:

$$
\left\|\Delta \tau_{\mathrm{s}}\right\|=\int_{\mathrm{t}_{\mathrm{k}}}^{\mathrm{t}}\left\|\dot{\boldsymbol{\tau}}_{\mathrm{cons}}(\mathrm{s})\right\| \mathrm{ds}=\left(\mathrm{t}-\mathrm{t}_{\mathrm{k}}\right)\left\|\boldsymbol{\tau}_{\mathrm{cons}}(\mathrm{s})\right\| \leq\left(\mathrm{t}-\mathrm{t}_{\mathrm{k}}\right) \gamma,
$$

which means that when $\mathrm{t} \rightarrow \mathrm{t}_{\mathrm{k}+1}, \mathrm{t}-\mathrm{t}_{\mathrm{k}}=\mathrm{t}^{*} \geq \frac{\left\|\Delta \tau_{\mathrm{s}}\right\|}{\gamma}$. Obviously, $\left\|\Delta \boldsymbol{\tau}_{\mathrm{s}}\right\|>0$, thus $\mathrm{t}^{*}>0$ and Zeno-free is guaranteed according to the above analysis.

\section{Numerical Simulations}

In this section, the numerical simulation of a cableless non-contact close-proximity formation satellite was performed. With various advantages such as fast response, insensitivity to parameter changes, and simple physical implementation, the time-triggering mechanism-based sliding mode control has been widely used in various nonlinear systems $[33,34]$. In order to illustrate the characteristics of the approach proposed in this paper more completely, this section introduces the linear sliding mode controller (SMC) for comparative simulations, which can be designed as follows:

$$
\begin{aligned}
& \mathbf{s}=\boldsymbol{\omega}_{\mathrm{sp}, \mathrm{s}}+\mathrm{cq}_{\mathrm{sp}, \mathrm{s}} \\
& \boldsymbol{\tau}_{\mathrm{s}}=-\alpha|\mathbf{s}|^{\gamma} \operatorname{sgn}(\mathbf{s})-\beta \mathbf{s}-\mathrm{cJ}_{\mathrm{s}} \boldsymbol{\omega}_{\mathrm{sp}, \mathrm{s}}+\boldsymbol{\Delta}_{\mathrm{s}},
\end{aligned}
$$


where $c, \alpha, \beta$ and $\gamma$ denote the positive values that satisfy $0<\gamma<1$, the operation $|\cdot|$ and $\operatorname{sgn}(\cdot)$ denote the absolute value and the sign function of a vector, respectively. The simulation environment and the initial parameters information are shown in Table 1 . The parameters of the designed controller are shown in Table 2.

Table 1. Simulation environment and initial parameters of the non-contact close-proximity formation satellite (Case1).

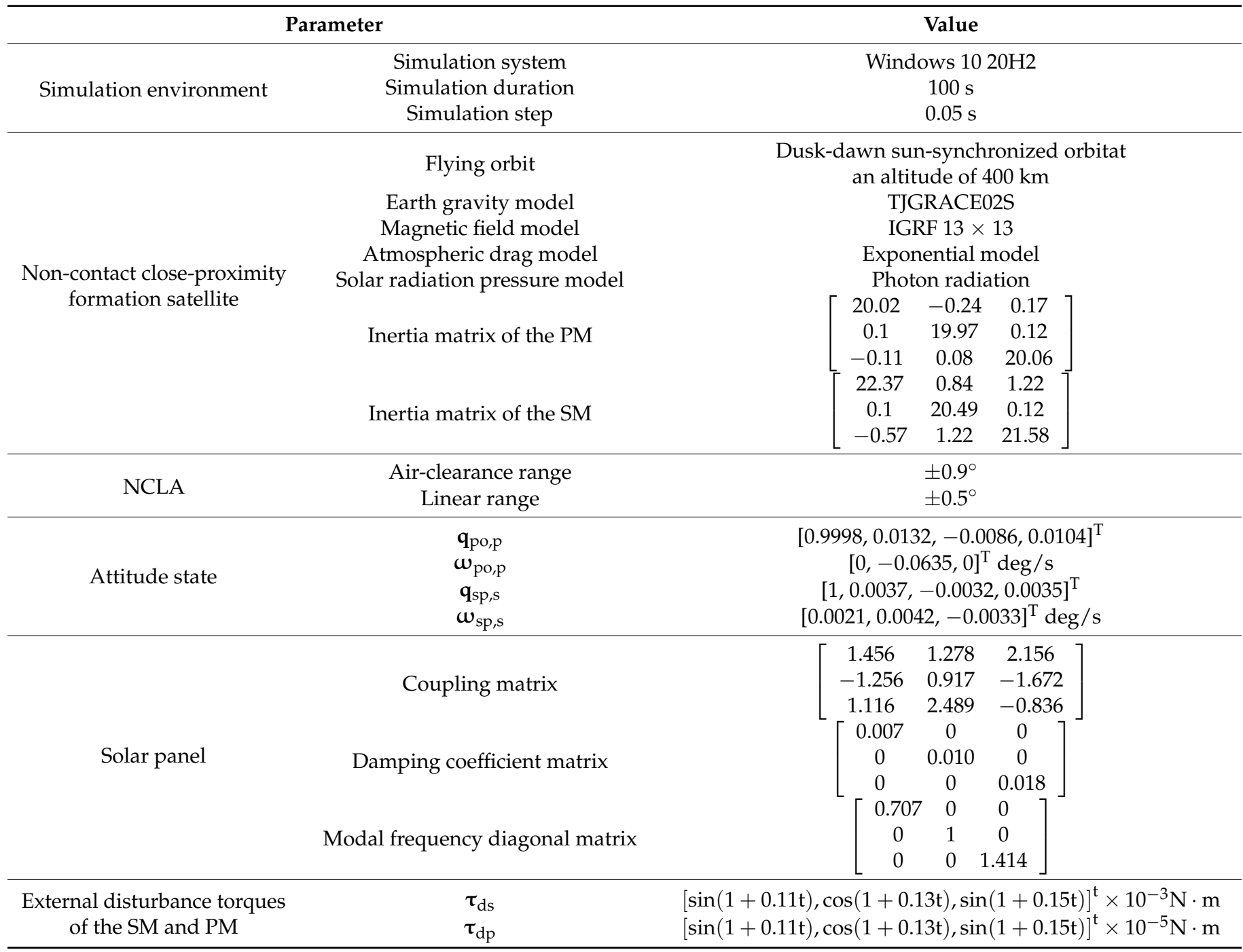

Table 2. Parameters of the designed controller (Case1).

\begin{tabular}{ccc}
\hline Parameter & & Value \\
\hline \multirow{3}{*}{ SMC } & $c$ & 5 \\
& $\alpha$ & 0.95 \\
& $\beta$ & 3 \\
& $\gamma$ & 0.95 \\
\hline Proposed approach & $\delta$ & 1.1 \\
& $\varepsilon$ & 58 \\
& $\mathbf{K}_{\mathrm{ps}}$ & $\operatorname{diag}(-52,-49,-51)$ \\
& $\mathbf{K}_{\mathrm{ds}}$ & $\operatorname{diag}(-77,-72,-75)$ \\
& $\mathbf{K}_{\mathrm{pp}}$ & $\operatorname{diag}(-41,-39,-42)$ \\
& $\mathbf{K}_{\mathrm{dp}}$ & $\operatorname{diag}(-102,-97,-103)$ \\
\hline
\end{tabular}


The simulation results of the SM are shown in Figures 4-8. Figures 4-6 show that the convergence of the attitude angle and the angular velocity could be realized by using both the SMC and the proposed approach. The proposed approach could achieve a faster convergence rate than the SMC. Meanwhile, the relative attitude angle of the two modules did not exceed the linear range of the NCLA, which indicated that the high precision control of the PM could be accomplished. Moreover, it can be seen that the time response of the attitude angle and angular velocity of the SM showed different levels of oscillation under the proposed approach. This was acceptable because the SM only needed to achieve rapid tracking control of the PM and to ensure that the NCLA was maintained in the linear range.
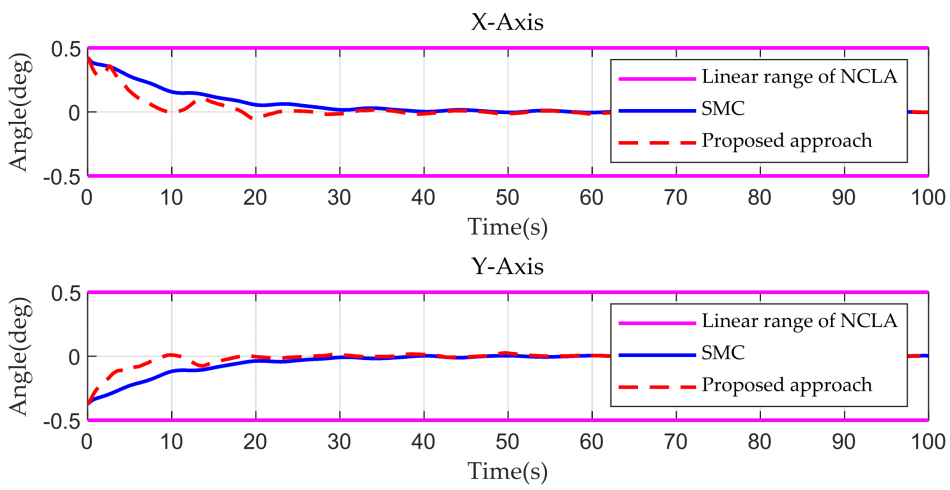

Z-Axis

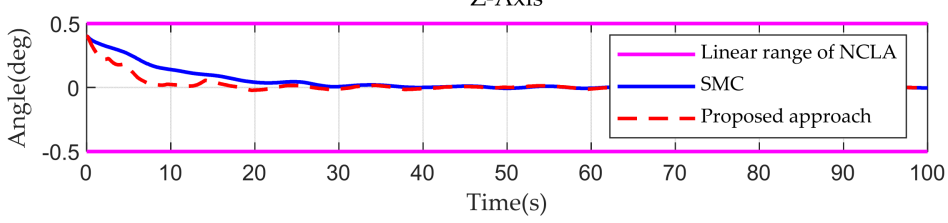

Figure 4. Attitude angle of the SM.

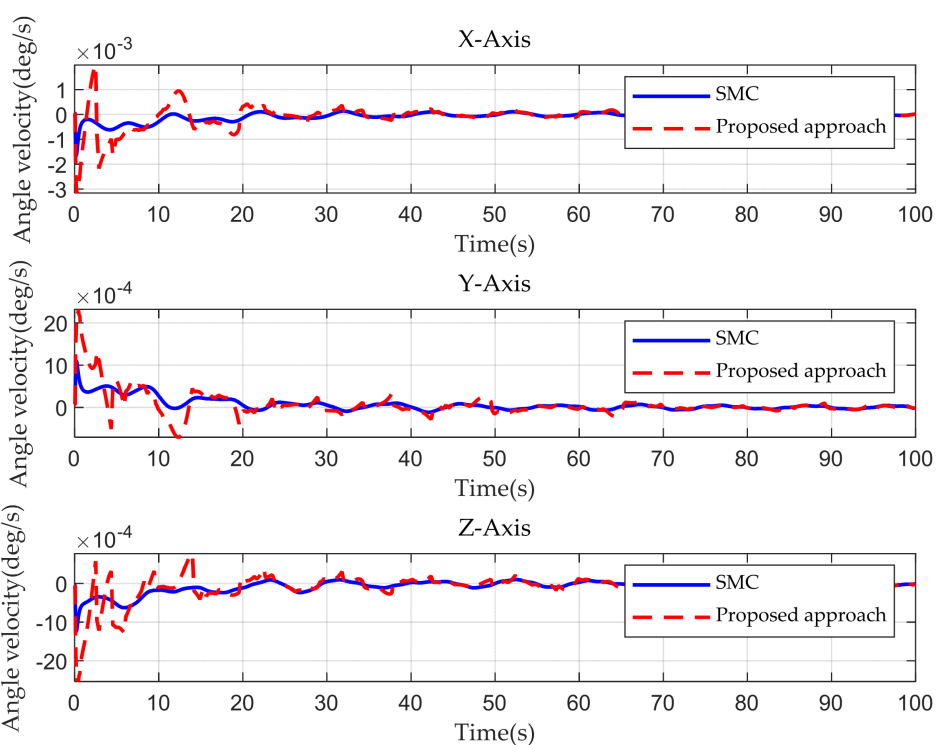

Figure 5. Angular velocity of the SM. 

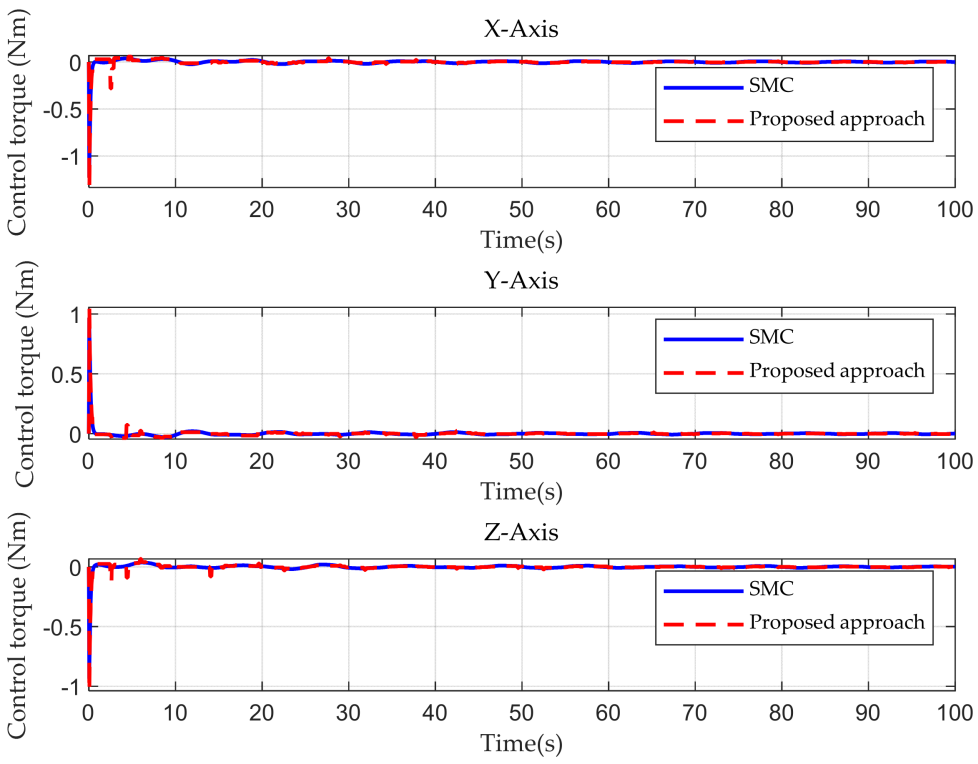

Figure 6. Control torque of the SM.

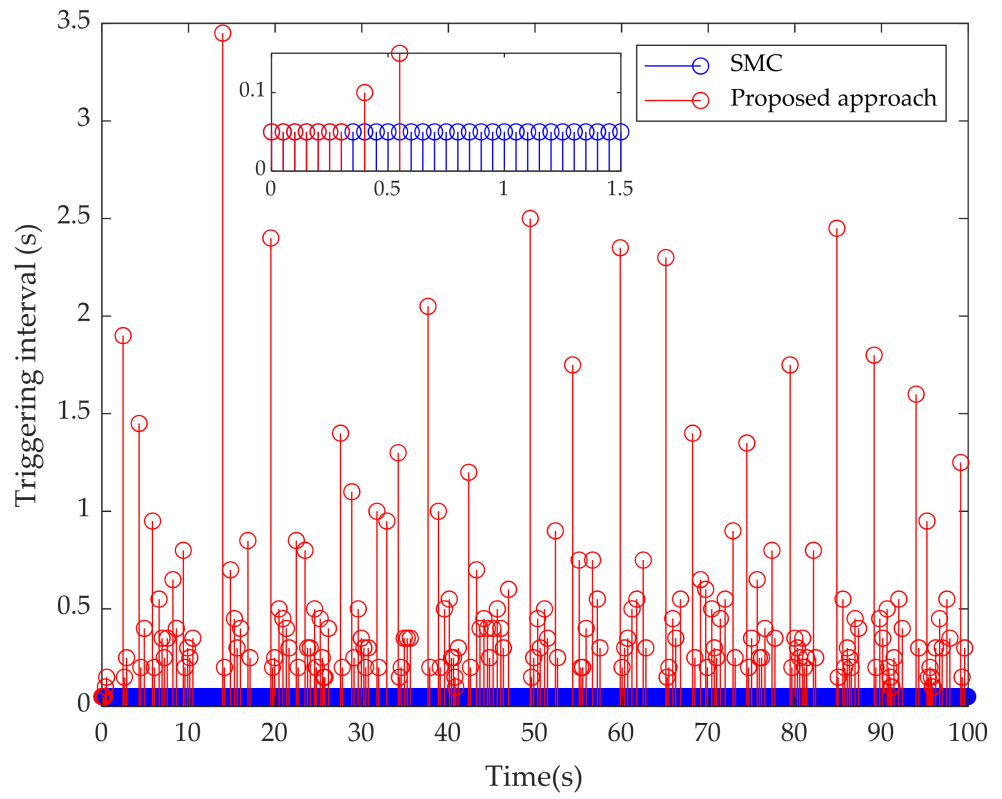

Figure 7. Triggering interval.

As shown in Figure 7, due to the time-triggered feature, the control signal of SMC was updated periodically. However, benefiting from the event-triggering mechanism, the maximum interval reached $3.45 \mathrm{~s}$ under the proposed approach. Meanwhile, the number of communication times is shown in Figure 8, from which we can see that the communication time under the proposed approach was 196 , which is a $90 \%$ reduction compared to the SMC.

The time response of the triggering condition is given in Figure 9, from which we can see that $\left\|\Delta \tau_{\mathrm{s}}\right\|$ was rarely lager than $\delta\|\mathbf{X}\|$ (due to the influence of flexing components such as solar panels, the SM will still perform a number of event-triggers to suppress this effect), indicating that the closed-loop system tended to be stabilized. 


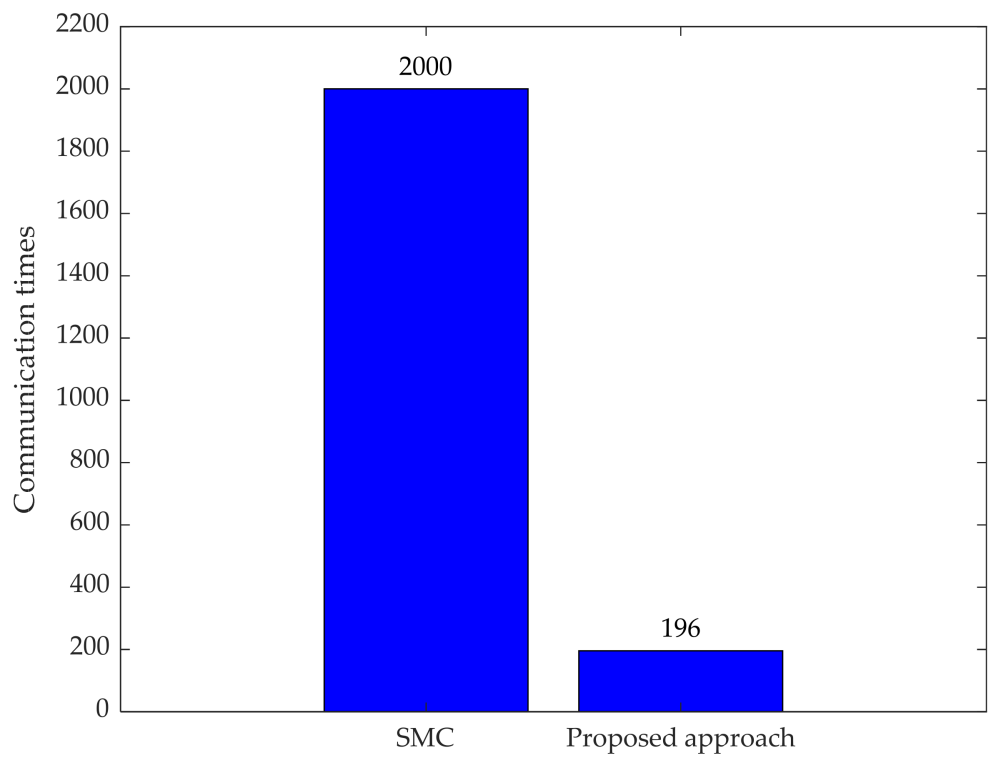

Figure 8. Number of communication times.

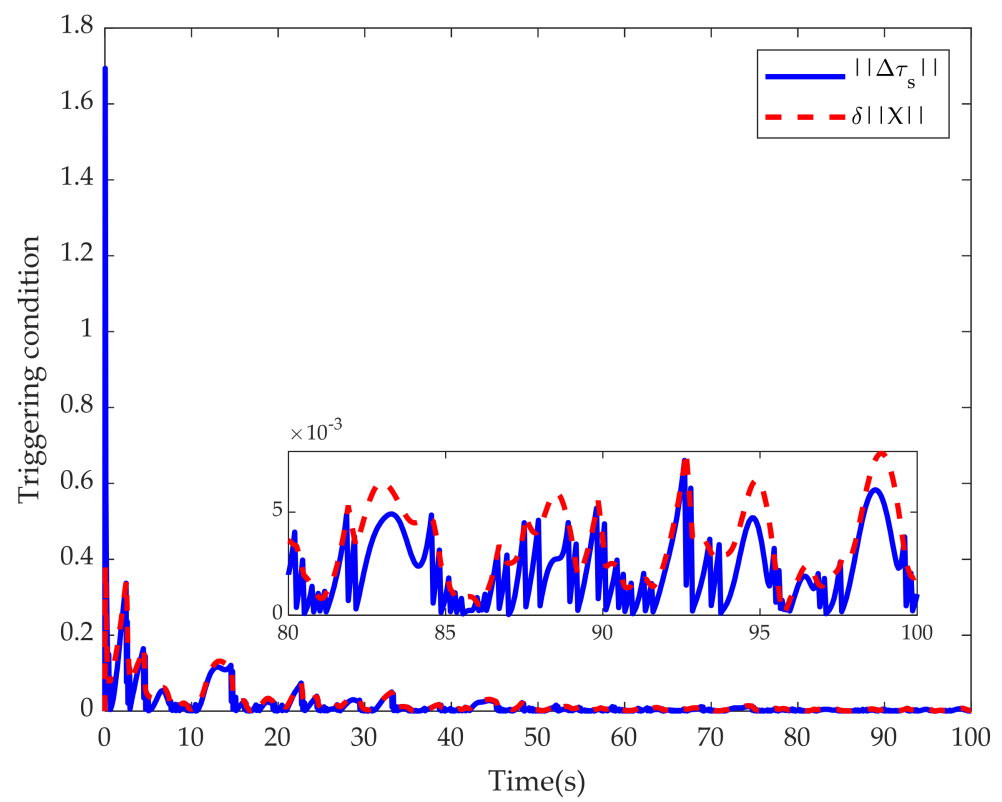

Figure 9. Triggering condition.

Moreover, to demonstrate how parameters $\delta$ and $\varepsilon$ influenced the communication times, Cases 2 and 3 were conducted. All the conditions and parameters of Cases 2 and 3 were the same as in Case 1 except for the parameters $\delta$ and $\varepsilon$. The simulation results are shown in Table 3, from which we can see thate the smaller values of $\delta$ and $\varepsilon$ resulted in a higher communication rate.

Table 3. Effect of the parameters $\delta$ and $\varepsilon$.

\begin{tabular}{ccccc}
\hline Indexes & $\boldsymbol{\delta}$ & $\boldsymbol{\varepsilon}$ & NTI $^{\mathbf{1}}$ & PRCT $^{\mathbf{2}}$ \\
\hline Case 1 & 1.10 & 58 & 196 & $90.4 \%$ \\
Case 2 & 0.8 & 58 & 208 & $89.6 \%$ \\
Case 3 & 0.8 & 50 & 232 & $88.4 \%$ \\
\hline
\end{tabular}

${ }^{1}$ NTI denotes the number of the triggering instants. ${ }^{2}$ PRCT denotes the percentage reduction in communication times. 
The simulation results of the PM are shown in Figures 10 and 11 . The attitude angle and angular velocity curve of the PM could converge to zero in $30 \mathrm{~s}$; the attitude accuracy and stability reached $2 \times 10^{-4}(\mathrm{deg})$ and $5 \times 10^{-6}(\mathrm{deg} / \mathrm{s})$ respectively, proving the superb vibration isolation capability and attitude control performance of the PM.

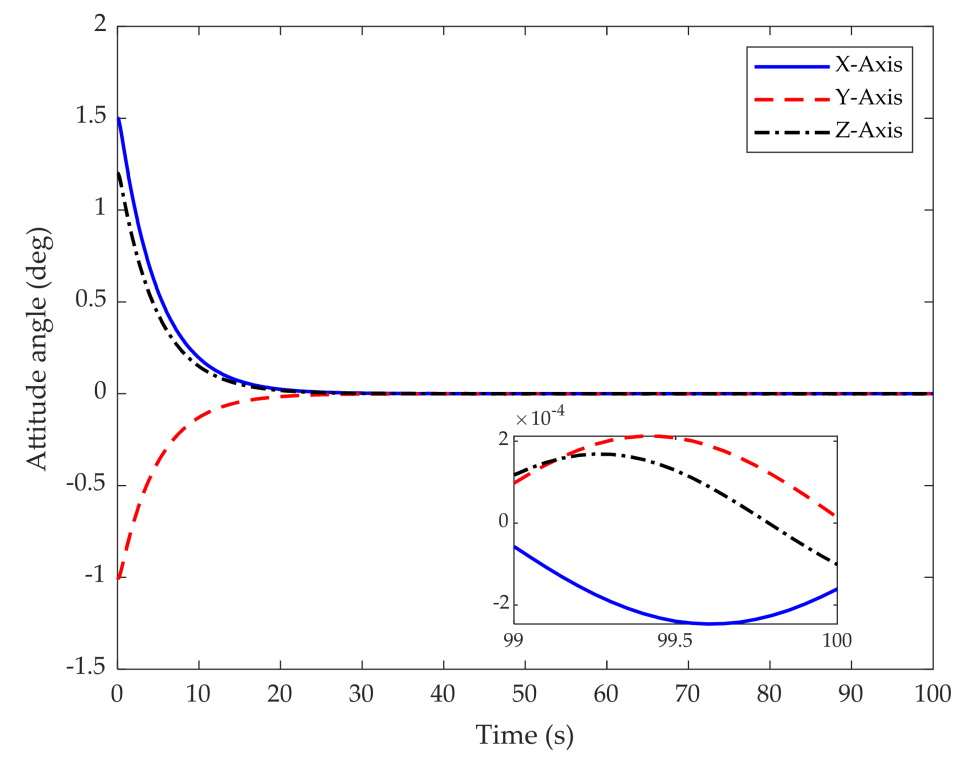

Figure 10. Attitude angle of the PM.

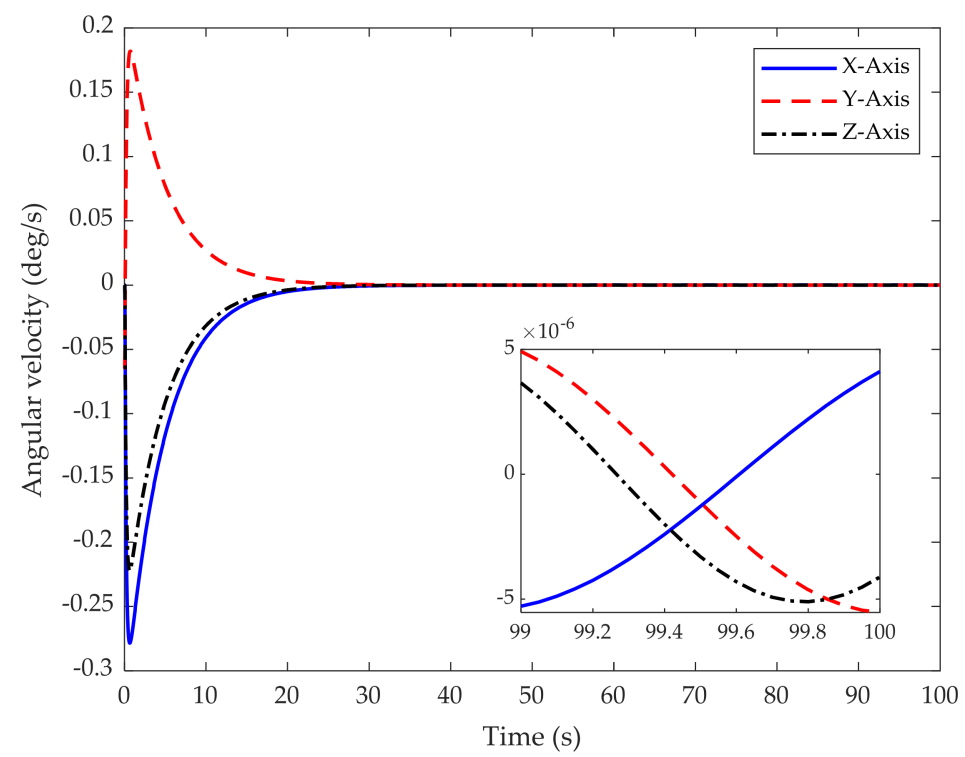

Figure 11. Angular velocity of the PM.

The above-mentioned simulation results clearly demonstrate that the event-triggered attitude tracking controller for the SM can achieve control demand with a significantly smaller resource utilization. The comparison of the control performance of the two approaches are shown in Table 4. 
Table 4. Controller performance comparison.

\begin{tabular}{|c|c|c|}
\hline Indexes & SMC & Proposed Approach \\
\hline Maintaining the linear range of the NCLA & Success & Success \\
\hline \multirow{4}{*}{$\begin{array}{c}\text { Convergence rate of the SM } \\
\text { Maximum communication interval } \\
\text { Communication times (Reduction rate) }\end{array}$} & $29 \mathrm{~s}$ & 22 s (slightly oscillating) \\
\hline & $23 \mathrm{~s}$ & 25 s (clearly oscillating) \\
\hline & $0.05 \mathrm{~s}$ & $3.45 \mathrm{~s}$ \\
\hline & $2000(-)$ & $196(90.4 \%)$ \\
\hline
\end{tabular}

\section{Conclusions}

This research sought to address the problem of limited on-board resources and system latency of the cableless non-contact close-proximity formation satellites. In this paper, an event-triggered attitude tracking controller was proposed. To reduce the number of communications between the two modules, an event-triggering mechanism was designed to determine the update time of the control signal and to avoid the Zeno phenomenon. The simulation results demonstrate the feasibility and effectiveness of the proposed approach. The communication burden between the two modules was significantly reduced by $90 \%$. This shows that, in a future where plug-and-play accessories are used on a large scale and where modularity is the main trend, the non-contact close-proximity formation satellite could still achieve control demand with a significantly smaller resource utilization. Meanwhile, the relative attitude angles of the two modules did not exceed the linear range of the NCLA, indicating that the high-precision control of the PM could be accomplished. Furthermore, it is noted that there were limitations in the trigger conditions under the influence of flexible components. Therefore, the improvement of the triggering mechanism and control law could become the focus of future research.

Author Contributions: Conceptualization, J.Q. and H.L.; methodology, J.Q.; software, J.Q.; validation, J.Q., H.L., Y.X., Z.Z. and C.Y.; formal analysis, H.L.; investigation, J.Q. and Y.X.; resources, Z.Z. and C.Y.; writing—original draft preparation, J.Q.; writing—review and editing, H.L., Y.X., Z.Z. and C.Y. All authors have read and agreed to the published version of the manuscript.

Funding: This work was supported in part by the key program of Chinese science and technology ministry (Grant No. 2020YFC2200502, 2020YFC2200801), National Natural Science Foundation of China (12172168), and Natural Science Foundation of Shanghai (19ZR1453300).

Institutional Review Board Statement: Not applicable.

Informed Consent Statement: Not applicable.

Conflicts of Interest: The authors declare no conflict of interest.

\section{References}

1. Lian, X.B.; Zhang, J.X.; Yang, J.K.; Lu, Z.K.; Zhang, Y.; Song, Y.Q. The determination for ideal release point of test masses in drag-free satellites for the detection of gravitational waves. Adv. Space Res. 2021, 67, 824-833. [CrossRef]

2. Li, Z.; Zheng, J.H. Orbit determination for a space-based gravitational wave observatory. Acta Astronaut. 2021, 185, 170-178. [CrossRef]

3. Wahballah, W.A.; Eltohamy, F.; Bazan, T.M. Influence of Attitude Parameters on Image Quality of Very High-Resolution Satellite Telescopes. IEEE Trans. Aerosp. Electron. Syst. 2021, 57, 1177-1183. [CrossRef]

4. Sanfedino, F.; Preda, V.; Pommier-Budinger, V.; Alazard, D.; Boquet, F.; Bennani, S. Robust active mirror control based on hybrid sensing for spacecraft line-of-sight stabilization. IEEE Trans. Control Syst. Technol. 2021, 29, 220-235. [CrossRef]

5. Jiang, C.S.; Liu, Y.J.; Jiang, Y.; Li, H.N. Orbital Design and Control for Jupiter-Observation Spacecraft. Aerospace 2021, 8, 282. [CrossRef]

6. Almazrouei, A.; Khan, A.; Almesmari, A.; Ahmed, B.; Ali, A.M.; Ali, A.; Alya, A. A Complete Mission Concept Design and Analysis of the Student-Led CubeSat Project: Light-1. Aerospace 2021, 8, 247. [CrossRef]

7. Gonzales, M.; Pedreiro, N.; Brookes, K.; Roth, D.; Foster, B. Unprecedented vibration isolation demonstration using the disturbance-free payload concept. AIAA Guid. Navig. Control Conf. 2004, 6, 5247.

8. Tajdaran, K.; Dewell, L.D.; Eason, E.V.; Bell, R.M.; Liu, K.C.; Bolcar, M.R.; Sacks, L.W.; Crooke, J.A.; Blaurock, C. Telescope line-of-sight slew control and agility with non-contact vibration isolation for the large ultraviolet/optical /infrared (LUVOIR) surveyor concept. SPIE Conf. 2017, 10698, 106983Y. 
9. Li, Q.; Liu, L.; Deng, Y.F.; Tang, S.; Zhao, Y.B. Twistor-based synchronous sliding mode control of spacecraft attitude and position. Chin. J. Aeronaut. 2018, 31, 1153-1164. [CrossRef]

10. Liao, H.; Xie, J.J.; Li, S.; Tang, Z.X.; Xu, Y.; Zhao, Y.B. Stringent three-axis stability control for novel non-contact satellite using embedded second-order noise estimator. Adv. Space Res. 2021, 69, 1619-1630. [CrossRef]

11. Rigatos, G.; Siano, P.; Selisteanu, D.; Precup, R.E. Nonlinear optimal control of oxygen and carbon dioxide levels in blood. Intell. Ind. Syst. 2017, 3, 61-75. [CrossRef]

12. Chen, T.; Babanin, A.; MUHAMMAD, A.; Bert, C.; Cyj, C. Modified Evolved Bat Algorithm of Fuzzy Optimal Control for Complex Nonlinear Systems. Rom. J. Inf. Sci. Tech. 2020, 23, T28-T40.

13. Zamfirache, I.A.; Precup, R.E.; Roman, R.C.; Petriu, E.M. Reinforcement Learning-based control using Q-learning and gravitational search algorithm with experimental validation on a nonlinear servo system. Inf. Sci. 2022, 583, 99-120. [CrossRef]

14. Zhou, J.; Liu, L.; Wang, Z.; Lil, J.; Liao, H.; Deng, Y. On pointing accuracy and pointing stability of disturbance-free payload using umbilical connection. In Proceedings of the 37th Chinese Control Conference, Wuhan, China, 25-27 July 2018; pp. 1591-1596.

15. Yang, H.J.; Liu, L.; Liu, Y.; Li, X.G. Modeling and Micro-vibration Control of Flexible Cable for Disturbance-Free Payload Spacecraft. Microgravity Sci. Technol. 2021, 33, 1-16. [CrossRef]

16. $\mathrm{Wu}, \mathrm{C} . ; \mathrm{Kong}$, X.R.; Liu, Y.F.; Chen, Z.P. Coupling characteristics analysis for the disturbance free payload spacecraft. Acta Astronaut. 2017, 138, 407-416. [CrossRef]

17. Kong, Y.F.; Huang, H. Performance enhancement of disturbance-free payload with a novel design of architecture and control. Acta Astronaut. 2019, 159, 238-249. [CrossRef]

18. Alto, P. System-Level Segmented Telescope Design Final Report. Available online: http://www.astrostrategictech.us/pdf/ projectfiles/Reports/17-SLSTD17-0001_FR_LM_2019_04_Public.pdf (accessed on 4 February 2022).

19. Song, K.; Ma, B.Q.; Yang, G.; Jiang, J.H.; Wei, R.Z.; Zhang, H.; Zhu, C.B. A rotation light weight wireless power transfer system for solar wing driving. IEEE Trans. Power Electron. 2018, 34, 8816-8830. [CrossRef]

20. Ge, X.H.; Ahmad, I.; Han, Q.L.; Wang, J.; Zhang, X.M. Dynamic event-triggered scheduling and control for vehicle active suspension over controller area network. Mech. Syst. Signal Process. 2021, 152, 107481. [CrossRef]

21. Li, S.; Li, Z.; Li, J.; Fernando, T.; Lu, H.H.; Wang, Q.L.; Liu, X.D. Application of event-triggered cubature Kalman filter for remote nonlinear state estimation in wireless sensor network. IEEE Trans. Ind. Electron. 2020, 68, 5133-5145. [CrossRef]

22. Liu, W.X.; Geng, Y.H.; Wu, B.L.; Wang, D.W. Neural-network-based adaptive event-triggered control for spacecraft attitude tracking. IEEE Trans. Neural Netw. Learn. Syst. 2019, 31, 4015-4024. [CrossRef]

23. Zhang, C.X.; Dai, M.Z.; Dong, P.; Leung, H.; Wang, J.H. Fault-tolerant attitude stabilization for spacecraft with low-frequency actuator updates: An integral-type event-triggered approach. IEEE Trans. Aerosp. Electron. Syst. 2020, 57, 729-737. [CrossRef]

24. Zhang, P.P.; Liu, T.F.; Jiang, Z.P. Event-triggered stabilization of a class of nonlinear time-delay systems. IEEE Trans. Autom. Control. 2020, 66, 421-428. [CrossRef]

25. Xu, S.D.; Wei, Z.T.; Huang, Z.; Wen, H.; Jin, D.P. Fuzzy-logic-based robust attitude control of networked spacecraft via eventtriggered mechanism. IEEE Trans. Aerosp. Electron. Syst. 2020, 57, 206-226. [CrossRef]

26. Zhang, C.X.; Dai, M.Z.; Wu, J.; Xiao, B.; Li, B.; Wang, M.J. Neural-networks and event-based fault-tolerant control for spacecraft attitude stabilization. Aerosp. Sci. Technol. 2021, 114, 106746. [CrossRef]

27. Di, F.Q.; Li, A.J.; Guo, Y.; Xie, C.Q.; Wang, C.Q. Event-triggered sliding mode attitude coordinated control for spacecraft formation flying system with disturbances. Acta Astronaut. 2021, 188, 121-129. [CrossRef]

28. Xing, L.; Zhang, J.Q.; Liu, C.; Zhang, X. Fuzzy-logic-based adaptive event-triggered sliding mode control for spacecraft attitude tracking. Aerosp. Sci. Technol. 2021, 108, 106394. [CrossRef]

29. Chi, W.C.; Ma, H.; Wang, C.H.; Zhao, T.Y. Research on Control of Stewart Platform Integrating Small Attitude Maneuver and Vibration Isolation for High-Precision Payloads on Spacecraft. Aerospace 2021, 8, 333. [CrossRef]

30. Papakonstantinou, C.; Lappas, V.; Kostopoulos, V. A Gimballed Control Moment Gyroscope Cluster Design for Spacecraft Attitude Control. Aerospace 2021, 8, 273. [CrossRef]

31. Gaude, A.; Lappas, V. Design and Structural Analysis of a Control Moment Gyroscope (CMG) Actuator for CubeSats. Aerospace 2020, 7, 55. [CrossRef]

32. Liao, H.; Xu, Y.F.; Zhu, Z.; Deng, Y.F.; Zhao, Y.B. A new design of drag-free and attitude control based on non-contact satellite. ISA Trans. 2019, 88, 62-72. [CrossRef]

33. Lee, D. Fault-tolerant finite-time controller for attitude tracking of rigid spacecraft using intermediate quaternion. IEEE Trans. Aerosp. Electron. Syst. 2020, 57, 540-553. [CrossRef]

34. Fu, J.B.; Liu, M.; Cao, X.B.; Ang, L. Robust neural-network-based quasi-sliding-mode control for spacecraft-attitude maneuvering with prescribed performance. Aerosp. Sci. Technol. 2021, 112, 106667. [CrossRef] 